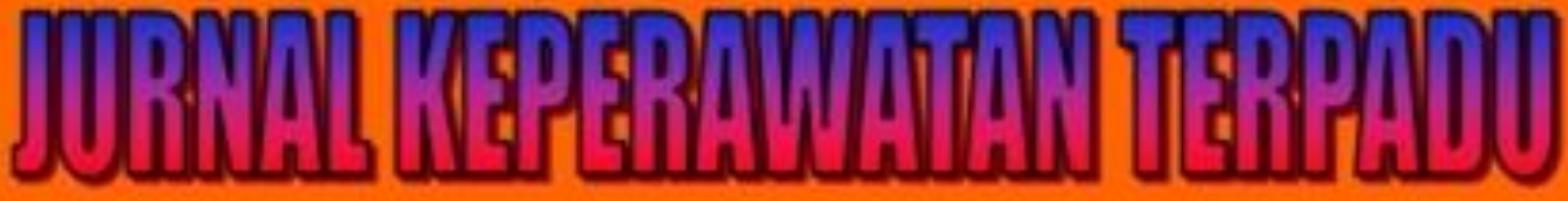

\section{Integrated Nursing Journal}

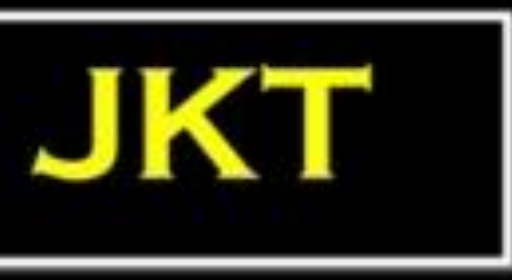

\section{p-ISSN: 2406-9698 (Print) e-ISSN: 2685-0710 (Online)}

\section{Vol. 2 No. 1 April 2020}

\section{KEMENTERIAN KESEHATAN RI}

\section{POLTEKKES MATARAM JURUSAN KEPERAWATAN}

Jalan Kesehatan V/10 Mataram NTB - http://jkt.poltekkes-mataram.ac.id 


\section{Vol. 2 No. 1 April 2020}

\section{Editorial Team}

\section{Editor-in-Chief}

Moh. Arip, Jurusan Keperawatan Poltekkes Kemenkes Mataram, Indonesia

\section{Editorial Board}

1. Mr. Frans Judea Samosir, Universitas Prima Indonesia, Indonesia

2. Baiq Kirana Kitna, Jurusan Keperawatan, Poltekkes Kemenkes Mataram, Indonesia

3. Irwan Budiana, Jurusan Keperawatan, Poltekkes Kemenkes Kupang, Indonesia

4. dr. Baskoro Tri Laksono, RS. Biomedika Mataram, Indonesia

5. Sitti Rusdianah, Jurusan Keperawatan, Poltekkes Kemenkes Mataram, Indonesia

6. Mira Utami Ningsih, Jurusan Keperawatan, Poltekkes Kemenkes Mataram, Indonesia

\section{Alamat Redaksi:}

Jurusan Keperawatan Mataram Poltekkes Kemenkes Mataram Kampus B

Jl. Kesehatan V No.10 Pajang Timur-Mataram NTB-Indonesia, 83127

Telepon: +62 370-621383

Fax: +62 370-631160

Email: jurnalkeperawatanterpadu2019@gmail.com

Laman: http://jkt.poltekkes-mataram.ac.id/index.php/home/index 


\section{Vol. 2, No. 1, April 2020}

\section{DAFTAR ISI}

Pengaruh Self Hypnosis Terhadap Respon Cemas Mahasiswa

Pada Ujian Tahap Akhir Program Di STIKes Buana Husada Ponorogo

Yudha Anggit Jiwantoro, Afifa Ika Kridawati, Danies Tunjung Pratiwi

Efektifitas Tepid Water Sponge Terhadap Penurunan Suhu Tubuh Pada Anak Dengan Masalah Keperawatan Hipertermia: Studi Kasus

Emy Mulyani, Nur Eni Lestari

Perilaku Pencegahan Penyakit Tidak Menular Pada Remaja Ambon

Hamdan Hariawan, Martini Tidore, Greeny Z. Rahakbau

Pengetahuan dan Sikap Perawat Berhubungan dengan Pelaksanaan Patient

Safety

Elisa Sulistia Fitri, Kusnanto, Herdina Maryanti

Efektivitas Art Therapy terhadap Pengetahuan dan Praktik Pemeliharaan Kesehatan Gigi pada Anak Usia Prasekolah

Linda Widyarani, Wiwi Kustio Priliana, Cecilya Kustanti

Konsep Diri Remaja Yang Mengalami Bullying

Puji Lestari, Liyanovitasari

Pengaruh Senam Tai Chi Terhadap Peningkatan Kualitas Tidur Lansia Di Balai Sosial Lanjut Usia Mandalika

Fathaillah Liestanto, Dina Fitriana

Hubungan Komunikasi Terapeutik Perawat Dengan Tingkat Kecemasan

Pasien Hemodialisa Di RSUD Dr Harjono Ponorogo

Ervan Nur Cholis, Rumpiati Rumpiati, Ike Sureni

Upaya Mengatasi Nyeri Post Op Sectio Cesaria Melalui Foot Massage Therapy Diruang Nifas RSUD Kota Mataram

Masadah, Cembun, Ridawati Sulaeman

Peningkatan Pemberdayaan Keluarga Melalui PINKESGA (Paket Informasi Keluarga) Kehamilan Dalam Mengambil Keputusan Merawat Ibu Hamil Mardiatun, Dewi Purnamawati, Ely Mawaddah
Page

$1-6$

Page

$7-14$

Page

$15-21$

Page

22-28

Page

29-39

Page

40-46

Page

$47-53$

Page

54-63

Page

$64-70$

Page

$70-78$ 


\title{
Pengaruh Senam Tai Chi Terhadap Peningkatan Kualitas Tidur Lansia Di Balai Sosial Lanjut Usia Mandalika
}

\author{
Fathaillah liestanto ${ }^{1}$, Dina Fithriana ${ }^{2}$ \\ ${ }^{1,2}$ Ilmu Keperawatan/ Keperawatan, Sekolah Tinggi Ilmu Kesehatan Mataram, Indonesia
}

\begin{abstract}
Abstrak
Peningkatan jumlah lansia akibat meningkatnya iusia harapan hidup tentunya akan menimbulkan beberapa masalah di bidang kesehatan, salah satunya adalah gangguan tidur. Tahun 2014 tercatat ada 19,2 juta jiwa lansia. Sedangkan tahun 2020 diperkirakan ledakan penduduk lansia menjadi 28,8 juta jiwa atau sebesar $11,34 \%$. Peningkatan gangguan tidur sejalan dengan peningkatan jumlah lansia tersebut, sehingga dibutuhkan intervensi non fakmakologis yang aman untuk mengatasinya. Penelitian ini bertujuan untuk mengetahui pengaruh Senam Tai Chi terhadap pemenuhan kebutuhan tidur lansia di Balai Sosial Lanjut Usia Mandalika Mataram. Penelitian ini merupakan penelian pre experimental dengan rancangan one grup pretest-posttest. Populasi dalam penelitian berjumlah 87 orang. Teknik sampling yang digunakan adalah Purposive Sampling. Sampel dalam penelitian ini sejumlah 19 orang. Alat ukur yang digunakan kuesioner instrumen baku PSQI (Pittsburgh Sleep Quality Index). Data dianalisis dengan statistik non parametrik dengan uji Wilcoxon. Hasil uji dengan $\rho$ sebesar 0,000 , menunjukkan ada pengaruh peningkatan kualitas tidur setelah dilakukan senam Tai Chi $(\alpha=0,05)$. Dapat disimpulkan bahwa senam Tai Chi yang dilakukan oleh responden dapat meningkatkan kualitas tidur lansia.
\end{abstract}

\section{Kata kunci: Lansia; Kualitas tidur; Senam Tai Chi}

\begin{abstract}
An increase in the number of elderly people due to an increase in life expectancy will certainly cause several problems in the health sector, one of which is sleep disorders. in 2014 there were 19.2 million elderly people. While in 2020 it is estimated that the elderly population explosion will be 28.8 million people or $11.34 \%$. The increase in sleep disorder has been happen along with the increase in the elderly population. Thus, a non pharmacology intervention is required to solve this problem. The purpose of this study was to determine the effect of Tai Chi exercise on meeting the needs of elderly sleepers at the Mandalika Mataram Elderly Social Center. This study is a pre-experimental study with the design of one group pretest-posttest. The population in the study amounted to 87 people. The sample was 19 people collected using Purposive sampling technique. The instrument used to collect data was a standard instrument questionnaire PSQI (Pittsburgh Sleep Quality Index). Data were analyzed using non- parametric statistics Wilcoxon signed rank test. Result shows that there is an effect of Tai Chi exercise towards the improvement of the quality of sleep among elderly. It could be concluded that Tai Chi Exercise can improve the quality of sleep of elderly people who have sleep disorders.
\end{abstract}

Keywords: Elderl,; Sleep Quality; Tai Chi Exercise

\author{
PENDAHULUAN
}


Peningkatan jumlah lansia akibat peningkatan usia harapan hidup tentunya akan menimbulkan beberapa masalah di bidang kesehatan, salah satunya adalah gangguan tidur. Semakin bertambahnya usia berpengaruh terhadap penurunan dari periode tidur (Prasadja, 2009). Jumlah lansia di Indonesia, tahun 2014 tercatat 19,2 juta jiwa pada tahun 2020 diperkirakan akan terjadi ledakan penduduk lansia menjadi 28,8 juta jiwa atau sebesar 11,34\%. (Kemenkes RI, 2015). Populasi lansia di NTB tahun 2016 sebanyak 164.000 jiwa dan diperkirakan meningkat hampir dua kali lipat pada tahun 2030 yaitu 288.900 jiwa. Menurut National Sleep Foundation tahun 2010 sekitar 67\% dari 1.508 lansia di Amerika usia 65 tahun keatas melaporkan mengalami insomnia dan sebanyak 7,3\% lansia mengeluhkan gangguan memulai dan mempertahankan tidur atau insomnia.

Perubahan kualitas tidur pada lanjut usia disebabkan oleh kemampuan fisik lanjut usia yang semakin menurun. Kemampuan fisik menurun karena kemampuan organ dalam tubuh yang menurun, seperti jantung, paru-paru dan ginjal (Prasadja, 2009). Faktor-faktor yang mempengaruhi kualitas tidur pada lanjut usia antara lain penyakit, stres psikologis, obat, nutrisi, lingkungan, motivasi, gaya hidup, dan latihan (senam) (Heny, 2013). Latihan/senam relaksasi dapat merangsang penurunan aktivitas saraf simpatis dan peningkatan aktifitas para simpatis yang berpengaruh pada penurunan hormon adrenalin, norepinefrin dan katekolamin serta vasodilatasi pada pembuluh darah. Hal ini selanjutnya mengakibatkan transpor oksigen ke seluruh tubuh terutama otak lancar sehingga dapat menurunkan tekanan darah dan nadi menjadi normal (Rahayu, 2008).

Senam Tai Chi adalah salah satu bentuk latihan atau seni untuk kesehatan fisik, keseimbangan jiwa, dan mental. Suatu kombinasi dari meditasi, fokus pada pernafasan, dan gerakan fisik dengan ritme tertentu (Sutanto, 2013). Gerakan Tai Chi dapat meningkatkan pelepasan nor adrenalin menurunkan kadar Kortisol, serta menurunkan aktivitas saraf simpatis yang membawa dampak denyut jantung yang stabil dan tekanan darah turun aktivitas saraf simpatis dan parasimpatis menjadi seimbang dan harmonis. Sehingga menstabilkan tekanan darah (Sutanto, 2013). Pada kondisi ini akan meningkatkan relaksasi lansia. Selain itu sekresi melatonin yang optimal dan pengaruh beta endhorphin dan membantu peningkatan pemenuhan kebutuhan tidur lansia (Rahayu, 2008). Penelitian ini bertujuan untuk meningkatkan kemandirian lansia dalam meningkatkan kualitas tidur dengan cara melakukan aktivitas fisik yaitu senam Tai Chi yang dapat diterapkan dalam aktivitas sehari-hari.

\section{METODE}

Penelitian ini menggunakan desain penelitian pre experimental dengan rancangan one grup pretest-posttest. Jumlah Populasi dalam penelitian terdiri dari lansia di BLSU Mandalika sebanyak 87 orang. Sampel sebanyak 19 orang yang diambil menggunakan tehnik purposive sampling. Kriteria inklusi adalah lansia yang mengalami gangguan tidur minimal selama bulan, lansia yang bersedia ikut serta dalam penelitian, mampu melakukan aktivitas ringan-sedang, tidak dalam pengobatan karena penyakit jantung dan tidak dalam terapi pembatasan aktivitas akibat fraktur atau penyakit lainnya. Kriteria eksklusi adalah lansia yang mengalami kelumpuhan dan lansia yang mengalami nyeri akibat 
gerakan atau mengalami intoleransi aktivitas. Penelitian ini dilakukan di Balai Sosial Lanjut Usia Mandalika Prov. NTB. Senam Tai Chi diberikan 3x selama 1 minggu dan selama 30 menit setiap sesi senam. Pemberian senam Tai Chi dilakukan dengan memutar video senam Tai Chi dan diperagakan oleh seorang pelatih senam, kemudian para responden mengikuti setiap gerakan senam yang diperagakan. Alat ukur yang digunakan dalam penilaian kualitas tidur pada penelitian ini adalah Pittsburgh Sleep Quality Index (PSQI). Data dianalisa dengan uji statistik menggunakan Wilcoxon Match Pair Test.

\section{HASIL PENELITIAN}

Tabel 1. Distribusi Responden Senam Tai Chi Berdasarkan Kelompok Umur menurut WHO (2011) di BSLU Mandalika ( $\mathrm{n}=19)$

\begin{tabular}{cccc}
\hline No & Usia & jumlah & \% \\
\hline 1 & $60-74$ (lanjut usia) & 19 & 100 \\
2 & $75-90$ (usia tua) & 0 & 0 \\
3 & $>90$ (sangat tua) & 0 & 0 \\
& Total & 19 & 100 \\
\hline
\end{tabular}

Sumber : Data Primer 2019

Tabel 1. menunjukkan bahwa kelompok umur responden terbanyak pada kelompok umur 60-74 (lanjut usia)dengan jumlah 19 responden (100\%).

Tabel 2. Distribusi Responden Berdasarkan Jenis Kelamin di BSLU Mandalika ( $\mathrm{n}=19)$.

\begin{tabular}{cccc}
\hline No & Jenis Kelamin & Jumlah & \% \\
\hline 1 & L & 6 & 32 \\
2 & $\mathrm{P}$ & 13 & 68 \\
& Total & 19 & 100 \\
\hline
\end{tabular}

Sumber : Data Primer 2019

Tabel 2. menunjukkan bahwa kelompok jenis kelamin responden sebagian besar berjenis kelamin perempuan dengan jumlah 13 responden $(68 \%)$.

Tabel 3. Distribusi Responden Berdasarkan Kelompok Tingkat Pendidikan di BSLU Mandalika $(n=19)$.

\begin{tabular}{cccc}
\hline No & Pendidikan & Jumlah & \% \\
\hline 1 & Tidak Sekolah & 8 & 42 \\
\hline 2 & SD & 11 & 58 \\
\hline & Total & 19 & 100 \\
\hline
\end{tabular}

Sumber : Data Primer 2019 
Tabel 3. menunjukkan bahwa kelompok tingkat pendidikan responden hampir sebagian besar pada kelompok SD (Sekolah Dasar) dengan jumlah 11 responden (58\%). 
Tabel 4. Distribusi nilai PSQI Responden Sebelum Melakukan Senam Tai Chi di BSLU Mandalika $(n=19)$.

\begin{tabular}{cccc}
\hline No & Kategori & Jumlah & \% \\
\hline 1 & Nilai $P S Q I$ Buruk & 19 & 100 \\
2 & Nilai $P S Q I$ Baik & 0 & 0 \\
& Total & 19 & 100 \\
\hline
\end{tabular}

Sumber : Data Primer 2019

Tabel 4. menunjukkan bahwa nilai PSQI sebelum melakukan senam Tai Chi semua responden kualitas tidur buruk berdasarkan kuesioner PSQI dengan jumlah 19 responden (100\%).

Tabel 5. Distribusi nilai PSQI Responden Setelah Melakukan Senam Tai Chi di BSLU Mandalika $(\mathrm{n}=19)$.

\begin{tabular}{cccc}
\hline No & Kategori & Jumlah & \% \\
\hline 1 & Nilai $P S Q I$ Buruk & 2 & 11 \\
2 & Nilai $P S Q I$ Baik & 17 & 89 \\
& Total & 19 & 100 \\
\hline
\end{tabular}

Sumber : Data Primer 2019

Tabel 5. menunjukkan bahwa nilai PSQI setelah melakukan senam Tai Chi sebagian besar responden kualitas tidur baik berdasarkan kuesioner PSQI dengan jumlah 17 responden (89\%).

Tabel 6. Nilai rata - rata Uji Wilcoxon Pengaruh Senam Tai Chi Terhadap peningkatan kualitas tidur pada lansia di BSLU Mandalika $(n=19)$.

\begin{tabular}{ccccc}
\hline Ketegori & N & Mean Rank & $\mathbf{Z}$ & Asymp. Sig \\
\hline Nilai $P S Q I$ & 19 & 9.00 & -3.654 & 0.000
\end{tabular}

Pre test-Post test

Sumber : Data Primer 2019

Tabel 6. menunjukkan Hasil perhitungan uji statistik menggunakan Wilcoxon Match Pair Test dengan taraf kepercayaan $95 \%$ untuk pengaruh Senam Tai Chi dengan nilai $\alpha=0,05$ diperoleh hasil nilai PSQI Pre-Post Test, dengan nilai signifikasi $\rho=0,000<\alpha(0,05)$ maka dapat disimpulkan bahwa hipotesis nul $\left(\mathrm{H}_{0}\right)$ ditolak atau hipotesis alternatif $\left(\mathrm{H}_{\mathrm{a}}\right)$ diterima, yang artinya ada pengaruh senam tai chi terhadap peningkatan kualitas tidur pada lansia di Balai Sosial Lanjut Usia. 


\section{PEMBAHASAN}

Hasil penelitian menunjukkan bahwa nilai PSQI diperoleh hasil uji statistik Wilcoxon Pair Test dengan nilai $\rho$ sebesar $0,000<\alpha=0,05\left(\mathrm{H}_{0}\right.$ ditolak), maka dapat disimpulkan bahwa terdapat pengaruh antara nilai PSQI sebelum dan sesudah dilakukan Senam Tai Chi. Keadaan ini menunjukkan terjadi peningkatan kualitas tidur setelah diberikan intervensi Senam Tai Chi pada lansia.

Menurut Darmojo (2009), sering bertambahnya usia terdapat penurunan periode tidur. Seorang usia lanjut membutuhkan waktu lebih lama untuk masuk tidur (berbaring lama di tempat tidur sebelum tidur) dan mempunyai lebih sedikit waktu tidur nyenyakn, sehingga seseorang yang tidak mendapatkan kualitas tidur yang baik, orang tersebut memperlihatkan perasaan lelah, mudah terangsang dan gelisah, lesu dan apatis, kehitaman di sekitar mata, kelopak mata bengkak, konjungtiva merah, mata perih, perhatian terpecah-pecah, sakit kepala dan sering menguap atau mengantuk.

Menurut (Sumitra, 2015) berbagai penyebab lansia mengalami masalah gangguan tidur atau tidak mendapatkan kualitas tidur yang maksimal disebabkan oleh beberapa factor yaitu ;usia, Jenis kelamin, Pekerjaan, Gaya hidup (merokok \& minum kopi), Status kesehatan, Psikologis (cemas ataupun stres) Selanjutnya menurut (Herlianto, 2005) dalam (Ghadafi, 2011) menjelaskan bahwa Tai Chi menyeimbangkan energi, dengan demikian saat keseimbangan alami tubuh dan pikiran didapat, stres dana cemaspun berkurang dengan berfokus pada gerakan yang dikendalikan, pikiran teralihkan dari ketegangan atau stres yang sedang dialami dan sangat berpengaruh untuk kesehatan fisik dan psikologi. Beberapa faktor yang paling mencetuskan penurunan kualitas tidur adalah faktor usia, jenis kelamin, pekerjaan ,psikologi (stress dan cemas), status kesehatan, gaya hidup (merokok dan minum kopi).

Senam Tai Chi adalah salah satu bentuk latihan atau seni untuk kesehatan fisik, keseimbangan jiwa, dan mental. Suatu kombinasi dari meditasi, fokus pada pernafasan, dan gerakan fisik dengan ritme tertentu (Sutanto, 2013). Senam Tai Chi yang dilakukan secara teratur terbukti dapat meningkatkan kesehatan fisik dan jiwa, yaitu adanya unsur meditasi, teknik relaksasi, pernafasan dan terapi biofeedback, karena gerakan Tai Chi meliputi body-mind-soul-breath membawa dampak positif pada jantung berupa denyut jantung yang stabil serta turunnya tekanan darah menuju normal. Gerakan Tai Chi dapat meningkatkan pelepasan nor adrenalin menurunkan kadar Kortisol, serta menurunkan aktivitas saraf simpatis yang membawa dampak denyut jantung yang stabil dan tekanan darah turun. aktivitas saraf simpatis dan parasimpatis menjadi seimbang dan harmonis. Hal ini disebabkan karena aktivitas saraf simpatis dan parasimpatis menjadi seimbang dan harmoni. Hal sangat membantu lansia menjadi lebih relaks dan akan memperbaiki kualitas tidur.

Hasil penelitian ini menunjukkan adanya peningkatan kualitas tidur yang berbeda-beda, namun jika dirata-ratakan nilai PSIQ sebelum senam Tai Chi adalah 10 dan setelah senam Tai Chi 
adalah 4. Menurut peneliti, yang menyebabkan perbedaan peningkatan kualitas tidur responden pada penelitian ini ada beberapa faktor yaitu yang pertama adalah faktor gaya hidup yaitu minum kopi dan merokok maka cenderung seseorang akan insomnia. Menurut Darmojo (2009), nikotin yang terkandung dalam asap rokok berkerja sebagai stimulant yang membuat penghisapnya terbangun dan waspada. Efek stimulan nikotin juga dapat menyebabkan nicotine withdrawal pada individu yang menggunakannnya. Setiap malam sehingga bisa menyebabkan gangguan tidur. Masalah lain pada kebiasaan merokok yaitu batuk dan masalah pernafasan di malam hari sehingga fatkor ini merupakan salah satu pencetus gagguan tidur. Sedangkan factor gaya hidup minum kopi, karena kandungan kafein dalam kopi, didalam tubuh kafein dapat terserap hampir sempurna. Efek perilaku dari kafein meliputi perasaan meningkatnya energy, tetap waspada, menurunnya fatigue dan rasa kantuk. Mekanisme aksi kafein berhubungan dengan kemampuannya dalam menghambat pengeluaran adenosine. Kafein menyebabkan peningkatan pengeluaran norepinefrin, epinefrin, dopamine dan serotonin, sehingga dapat membuat orang tetap waspada. Jika kafein dikonsumsi $>250 \mathrm{mg}$ dapat menyebabkan terjadinya sindrom intoksikasi yang meliputi gejala cemas, tegang, diuresis, takikardia, agitasi dan insomnia.

Faktor kedua adalah psikologi (cemas) yang dialami oleh masing - masing responden berbeda - beda, dari hasil wawancara peneliti kepada responden sebelum akan melakukan kegiatan Senam Tai Chi sebagian responden datang dengan keadaan cemas yang berbeda - beda penyebabnya, sebagaimana diktehui dimana strees dan kecemasan merupakan bagian di dalam kehidupan manusia sehari-hari. Kecemasan yang dialami pasien dapat merangsang system saraf simpatis untuk mengeluarkan katekolamin, glucagon dan hormon kortisol-steroid yang mempengaruhi SSP dalam meningkatkan rasa gelisah, frustasi, nafas cepat, hipertensi dan ketegangan otot. Demikian juga dapat menstimulasi fungsi RAS (Reticular Activating System) yang mengatur seluruh fase siklus tidur, meningkatkan sleep latency dan menurunkan efisiensi tidur yang meliputi peningkatan frekuensi bangun di malam hari (Puspitosari, 2011). Faktor psikologi tersebut berkaitan dengan faktor yang paling utama, yaitu tingkat konsentrasi, dan keseriusan responden. Cemas yang dialami responden tersebut menyebabkan beberapa responden merasa kurang dapat berkonsentrasi dengan baik, dan tidak dapat mengikuti senam dengan tingkat keseriusan yang baik dalam melakukan senam Tai Chi.

Faktor kesehatan merupakan keluhan terbanyak pada responden sebagian besar responden memiliki berbagai masalah kesehatan seperti penyait rematik, hipertensi, asma dan DM. Menurut Hardiwinoto (2010) menyatakan dalam sebuah penelitian, 15\% orang Amerika dilaporkan menderita penyakit kronis dan dua per tiganya dilaporkan mengalami masalah tidur. Dalam penelitian ini responden mengeluhkan jika nyeri terkadang sering membuat terbangun dimalam hari, hal tersebut membuatnya menjadi terjaga sehingga menurunkan kualitas tidur, namun banyak juga responden yang memiliki penyakit dapat mengontrol penyakitnya sehingga hal ini sangat membantu untuk meningkatkan status kesehatan pasien, sehingga dapat meningkatan kualitas tidur. 


\section{KESIMPULAN}

Terdapat pengaruh pemberian senam Tai Chi terhadap kualitas tidur lansia, dimana hampir semua lansia yang melakukan senam Tai Chi mendapatkan peningkatan kualitas tidur.

\section{DAFTAR PUSTAKA}

Dinas Kesehatan Provinsi NTB . (2017). Laporan Tahunan Data Kesehatan Provinsi NTB. NTB: Sub. Bagian Pencatatan dan pelaporan Dinas Kesehatan Provinsi NTB.

Ghadafi, Muhammad. (2011). Pengaruh latihan "Aerobik Lambat" Terhadap Daya Tahan Jantung Paru dan Komposisi Tubuh (Persentase Lemak Tubuh) Pada Lanjut Usia di Kota Surabaya.[Skripsi] FAKULTAS MIPA Universitas Negri Surabaya.

Heny, LP., Sutresna, I. N., \& Wira, P. (2013). Pengaruh masase punggung terhadap kualitas tidur lansia dengan insomnia di panti sosial tresna werdha wana seraya Denpasar

Kemenkes RI. (2015). Pelayanan dan peningkatan kesehatan usia lanjut. Tersedia dalam http:// www.kemenkes.go.id/ article/ view/15052700010/.

Notoatmodjo, S. (2010). Metodologi Penelitian Kesehatan. Jakarta: Rineka Cipta.

Prasadja. (2009). Ayo Bangun dengan Bugar karena Tidur yang Nyenyak. Jakarta: Mizan Publika.

Puspitosari. (2011).Gangguan Pola Tidur Pada Kelompok Usia Lanjut, Journal Kedokteran Trisakti, Januari-April, Vol.21, No 1.2014

Rahayu, S. (2008). Pengaruh pendidikan kesehatan tentang kemunduran fisik lansia terhadaptingkat depresipada lansia. Universitas Riau.

Sumitra. Nengah, dkk. (2016). Faktor Yang Menyebabkan Gangguan Tidur(Insomnia) Pada Lansia. Jurusan Keperawatan Politeknik Kesehatan Kemenkes Denpasar.

Sutanto, Jusuf. (2013). The Dancing Leader 3.0 Tai Chi untuk Perawat Membangun Keluarga Di Rumah dan Rumah Sakit. Jakarta : PT. Kompas Media Nusantara. 